\title{
Letter \\ Tight glycaemic control: intelligent technology or a nurse-wise strategy?
}

\author{
Mart J de Graaff ${ }^{1,2}$, Peter E Spronk ${ }^{1,3,4}$ and Marcus J Schultz ${ }^{1,2,3}$
}

\begin{abstract}
${ }^{1}$ Department of Intensive Care Medicine, Academic Medical Center, University of Amsterdam, Meibergdreef 9, 1105 AZ Amsterdam, The Netherlands ${ }^{2}$ Laboratory of Experimental Intensive Care and Anesthesiology, Academic Medical Center, University of Amsterdam, Meibergdreef 9 , 1105 AZ Amsterdam, The Netherlands

${ }^{3}$ Hermes Critical Care Group, Gelre Hospitals (location Lucas), Apeldoorn, The Netherlands

${ }^{4}$ Department of Intensive Care Medicine, Gelre Hospitals (location Lucas), Albert Schweitzerlaan 31, 7334 DZ Apeldoorn, The Netherlands
\end{abstract}

Corresponding author: Mart J de Graaff, m.j.degraaff@amc.uva.nl

Published: 24 September 2007

This article is online at http://ccforum.com/content/11/5/421

(c) 2007 BioMed Central Ltd

See related research by Shulman et al., http://ccforum.com/content/11/4/R75
Critical Care 2007, 11:421 (doi:10.1186/cc6124)

\section{Competing interests}

The authors declare that they have no competing interests.

\section{References}

1 Shulman R, Finney SJ, O'Sullivan C, Glynne PA, Greene R: Tight glycaemic control: a prospective observational study of a computerised decision-supported intensive insulin therapy protocol. Crit Care 2007, 11:R75.

2 Van den Berghe G, Wouters P, Weekers F, Verwaest C, Bruyninckx F, Schetz M, Vlasselaers D, Ferdinande P, Lauwers P, BouilIon R: Intensive insulin therapy in the critically ill patients. $N$ Engl J Med 2001, 345:1359-1367.

3 Van den Berghe G, Wilmer A, Hermans G, Meersseman W, Wouters PJ, Milants I, Van Wijngaerden E, Bobbaers H, Bouillon $\mathrm{R}$ : Intensive insulin therapy in the medical ICU. $N$ Engl J Med 2006, 354:449-461. unpublished data); they all are exceptionally complex and frequently difficult to follow. We recently had the opportunity to visit the Leuven hospital and were surprised to see their protocol, which is remarkably concise, far from complex, and consequently very easy to follow. In fact, their protocol is no more than a small set of written guidelines that nurses hardly ever use after having gained experience with it for some months, because (to quote the nurses) 'TGC is something you do by heart, not from a sheet of paper'.

In addition, the large number of blood glucose level (BGL) measurements (almost one BGL measurement every 75 minutes) with the tested computerized TGC protocol [1] is not comparable with the original studies of TGC $[2,3]$ or with current practice in Leuven. Rather, such frequent measurements may explain the high incidence of protocol violations: it was common for BGL measurements to be performed too infrequently or too late.

There is a need to standardize TGC. But let's start the easy way first: a simple protocol that forms a solid and practical basis for nurses. 